\title{
Sealing pseudo-aneurysms of the femoral artery with saline injection: a new technique
}

\author{
Daniel Périard ${ }^{1 *}$, MD; Marie-Antoinette Rey Meyer¹, MD; Daniel Hayoz¹, MD; Stéphane Cook², MD \\ 1. Service d'Angiologie, Hôpital Cantonal de Fribourg, Fribourg, Switzerland; 2. Service de Cardiologie, Hôpital Cantonal de \\ Fribourg, Fribourg, Switzerland
}

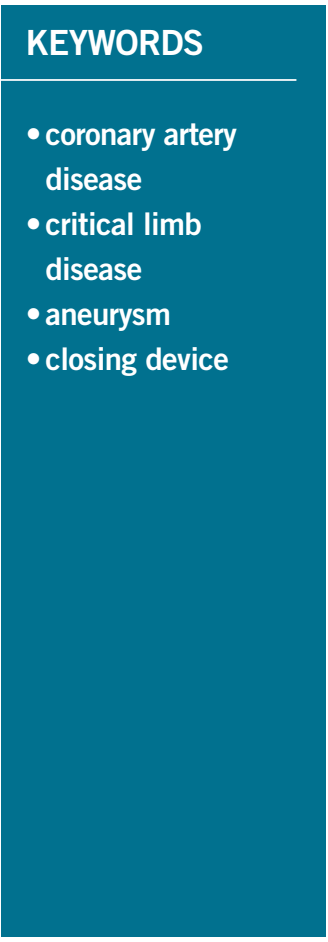

\begin{abstract}
Aims: Pseudo-aneurysm (PA) of the femoral artery is the most frequent complication after diagnostic or therapeutic catheterisation. PA may manifest with large and painful haematoma or compression of the adjacent nerve and vein. Among several therapeutic approaches, compression by injection of saline around the neck is a recent and promising method. To explore compression with saline as an alternative treatment for iatrogenic femoral artery PA was the aim of this study.
\end{abstract}

Methods and results: From December 2009 to January 2011, all consecutive patients with symptomatic PA were included in this study. After ultrasonic assessment, the PA neck was occluded by injection of a saline/ lidocaïne (0.2\%) mixture in the soft tissue at its vicinity, followed by a short echo-guided compression. Outcome was assessed at one and 30 days by duplex sonography. Eleven patients with PA requiring immediate treatment were included. All patients had at least one PA cavity. Moreover, four patients had multiple pulsatile cavities and seven patients had large thigh or abdominal haematoma, with either active bleeding, compression of adjacent organ or hypotension. Three patients had very short PA neck. The mean injected volume was $47 \pm 11 \mathrm{ml}$. The mean compression time until the PA was closed was $6 \pm 3$ minutes. At one and 30 days, all PA remained occluded without any complication related to the procedure.

Conclusions: Saline injection to seal PA is feasible, safe and very effective. The technique is rapid and well tolerated, and allows, after limited training, the closure of very large PA, even in case of emergency. This new technique is more comfortable for the patient and the operator, and surely more economical than thrombin injection or surgical arterial suture.

\footnotetext{
*Corresponding author: Service d'Angiologie, Hôpital Cantonal, 1700 Fribourg, Switzerland.
}

E-mail: periardd@h-fr.ch 


\section{Introduction}

Pseudo-aneurysm (PA) of the femoral artery is characterised by a disruption of the three arterial layers with blood flowing out of the vessel, through a neck of variable length, into the perivascular soft tissue. It is usually due to a complication of an endovascular procedure $^{1}$. Current options for the management of PA that require treatment include compression therapy, percutaneous thrombin injection, endovascular repair with prolonged balloon occlusion or placement of a covered stent, and open surgical repair. Closing PA with saline is a new and promising alternative. The technique was experimented with success in six patients by Lamonica and colleagues (unpublished data) ${ }^{2}$. Our own experience suggests that the method is feasible and safe. This study was designed to assess the efficacy and the safety of saline injection to close symptomatic PA of the femoral artery requiring urgent repair.

\section{Methods}

\section{PATIENT SELECTION}

From December 2009 to January 2011, all consecutive patients in our institution with a diagnosis of PA following coronary or peripheral artery endovascular procedure were evaluated for inclusion in this study. Patients with suspected PA were examined by the angiologist with a duplex scan (HD11; Philips Ultrasounds, Bothell, WA, USA). The location of the arterial flowing point, the morphology of the PA neck and cavity, and any related haematoma were precisely examined. Vessel dissection, arterio-venous shunt, any thrombosis and presence of sealing device were also systematically searched. Exclusion criteria were age $<18$ years, asymptomatic PA smaller than $2 \mathrm{~cm}$ diameter, PA with estimated high probability of spontaneous closure, and PA unrelated to recent endovascular procedure. Large or complex PA, painful PA, actively bleeding PA and haemodynamically unstable patients were not excluded from the study. All the patients gave their informed consent, and the study protocol was approved by the institution ethics committee.

\section{INTERVENTION}

After sonographic examination, the groin was disinfected and covered with sterile drape and the sonographic probe covered by a sterile cover. All patients had a peripheral catheter for atropine injection if necessary. A solution of $40 \mathrm{ml}$ saline and $10 \mathrm{ml}$ lidocaïne $1 \%$ was prepared in a $50 \mathrm{ml}$ syringe, mounted with a $9 \mathrm{~cm}, 21$ gauge, echoenhanced needle (Merit Medical systems, South Jordan, UT, USA). Under sonographic control, the solution was injected into the soft tissues around the flowing point and in the neck by multiple positioning of the needle tip. The solution was injected until an important oedema of the soft tissue was present all around the neck (Figure 1). If necessary, an additional $50 \mathrm{ml}$ syringe was used to obtain the oedema. The second aim of the large volume injection was to obtain a diffuse anaesthesia of the groin, which was essential to be able to apply a heavy compression that would not have been tolerated otherwise. The flowing point and the neck were then precisely and firmly compressed with the probe, under sonographic control, for a sufficient amount of time to allow thrombosis of the

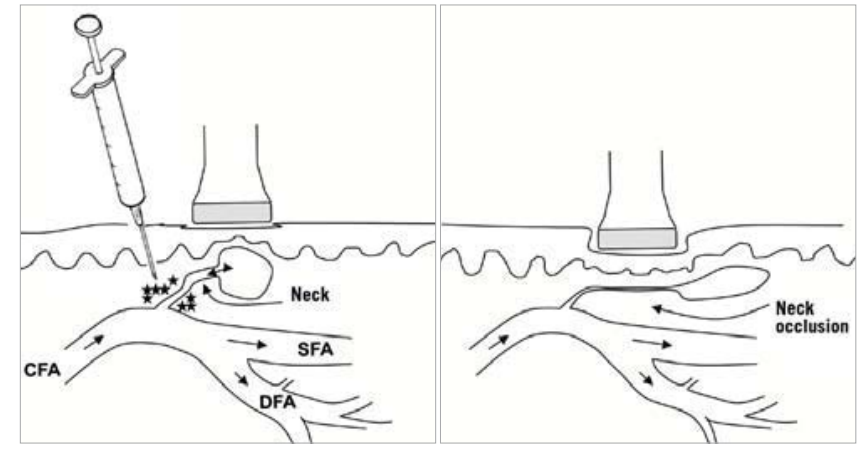

Figure 1. Method for PA sealing with saline-lidocaïn injection. Under sonographic guidance, a large volume of saline-lidocaïne is injected into the soft tissue around the neck. The tissue swelling and the local anaesthesia allow very efficient compression of the neck, until clotting of the flowing point. (C/S/DFA: common/superficial/ deep femoral artery).

neck and the flowing point (Figure 2). The compression was decreased every two minutes to assess the result. Once the PA was closed, patients were asked to stay in bed for 12 hours with an external elastic compression, in order to protect the clot from new rupture and to avoid excessive mobilisation and stretching of the tight haematoma. All patients were evaluated by clinical examination and duplex scan at 24 hours and one month.

\section{Results}

During the study period, fourteen patients with documented PA of the femoral artery were considered for inclusion in the study. Three patients were excluded for small, asymptomatic and partially thrombosed PA that did not require intervention. They were followed with duplex scans until spontaneous healing. The remaining 11 patients (mean \pm SD age $70 \pm 11$ ) were included in the study and all underwent the intervention. Their clinical characteristics are shown in Table 1. The PA was a complication of coronary angioplasty in seven patients, coronary angiography in two patients and peripheral artery angioplasty in two patients. The median delay between endovascular

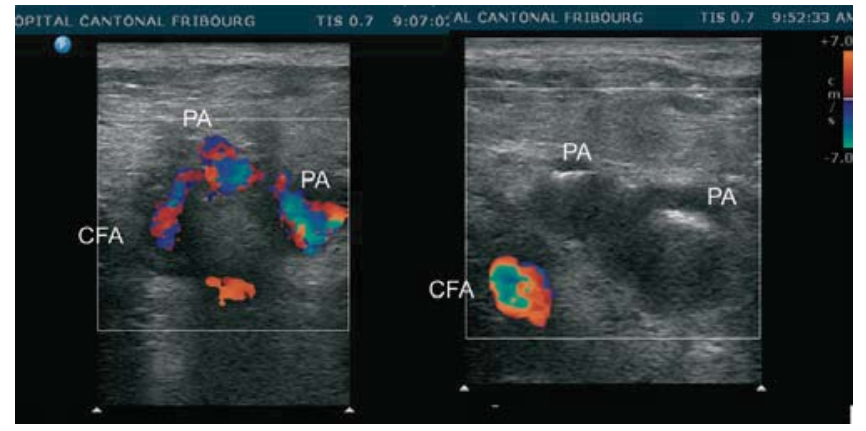

Figure 2. PA of the common femoral artery, with a long neck and two small pulsatile cavities. After compression for three minutes, the reassessment shows thrombosis of the neck and absence of residual flow in both PA cavities. 
Table 1. PA morphology and clinical characteristics of 11 patients included in the study. All PA were successfully treated by saline injection.

\begin{tabular}{|c|c|c|c|c|c|}
\hline Age/sex & Localisation & PA morphology / size & Neck & Cause & $\begin{array}{l}\text { Antithrombotic treatment } \\
\text { at time of PA closure }\end{array}$ \\
\hline 54 / M & CFA & single pulsatile cavity $4 \times 2 \mathrm{~cm}$ & long & failure of manual compression & $\begin{array}{l}\text { AAS clopidogrel } \\
\text { enoxaparin }\end{array}$ \\
\hline $80 / M$ & CFA & single pulsatile cavity $3 \times 2 \mathrm{~cm}$ & long & failure of closing device (Angio-Seal) & AAS clopidogrel heparin \\
\hline $62 / F$ & DFA & $\begin{array}{l}\text { double pulsatile cavity } 2 \times 1.5 \mathrm{~cm} \text { and } \\
1.5 \times 1 \mathrm{~cm} \text {, groin haematoma }\end{array}$ & long & $\begin{array}{l}\text { proximal DFA puncture and failure of } \\
\text { manual compression }\end{array}$ & AAS \\
\hline $69 / F$ & SFA & $\begin{array}{l}\text { double pulsatile cavity } 2 \times 1.5 \mathrm{~cm} \text { and } \\
2 \times 1 \mathrm{~cm} \text {, groin haematoma }\end{array}$ & long & $\begin{array}{l}\text { proximal SFA puncture and failure of } \\
\text { manual compression }\end{array}$ & AAS \\
\hline $81 / F$ & SFA & $\begin{array}{l}\text { single pulsatile cavity } 1.5 \times 1.5 \mathrm{~cm} \text { and } \\
\text { active bleeding in a large thigh } \\
\text { haematoma }\end{array}$ & $\begin{array}{l}\text { multiple, } \\
\text { long }\end{array}$ & $\begin{array}{l}\text { proximal SFA puncture and failure of } \\
\text { closing device (Angio-Seal pulled out } \\
\text { the vessel) }\end{array}$ & AAS clopidogrel \\
\hline $69 / M$ & SFA & $\begin{array}{l}\text { single pulsatile cavity, } 3 \times 1 \mathrm{~cm} \text {, along } \\
\text { the SFA }\end{array}$ & absent & $\begin{array}{l}\text { proximal SFA puncture and failure of } \\
\text { closing device (ExoSeal) }\end{array}$ & $\begin{array}{l}\text { AAS clopidogrel } \\
\text { enoxaparin }\end{array}$ \\
\hline 70 / M & CFA & $\begin{array}{l}\text { single pulsatile cavity } 2 \times 3 \mathrm{~cm} \text {, } \\
\text { retroperitoneal haematoma, hypovolemic } \\
\text { shock }\end{array}$ & long & $\begin{array}{l}\text { CFA puncture too proximal, failure of } \\
\text { manual compression }\end{array}$ & AAS heparin \\
\hline 59 / M & CFA & $\begin{array}{l}\text { large pulsatile cavity } 4 \times 4 \times 3.5 \mathrm{~cm} \text {, } \\
\text { compression of femoral nerve }\end{array}$ & short & failure of manual compression & AAS heparin \\
\hline $59 / M$ & CFA & $\begin{array}{l}\text { triple pulsatile cavity, each } 2 \times 2 \mathrm{~cm} \text {, } \\
\text { groin hematoma and percutaneous } \\
\text { arterial bleeding }\end{array}$ & $\begin{array}{l}\text { multiple, } \\
\text { long }\end{array}$ & failure of closing device (StarClose) & $\begin{array}{l}\text { AAS prasugrel } \\
\text { enoxaparin }\end{array}$ \\
\hline $78 / F$ & CFA & $\begin{array}{l}\text { single pulsatile cavity } 3 \times 2 \mathrm{~cm} \text { and } \\
\text { active bleeding in a large thigh } \\
\text { haematoma }\end{array}$ & short & failure of closing device (FemoSeal) & AAS heparin \\
\hline $87 / F$ & SFA & $\begin{array}{l}\text { triple pulsatile cavity, each } 2 \times 2 \mathrm{~cm} \text {, and } \\
\text { large groin haematoma } 13 \times 10 \times 9 \mathrm{~cm}\end{array}$ & long & failure of closing device (FemoSeal) & AAS enoxaparin \\
\hline
\end{tabular}

procedure and diagnosis of PA was one day (range 0 to 6). Ten patients were treated by saline injection on the same day, and one patient was treated 24 hours after diagnosis, when reassessment showed PA enlargement. In six patients, the puncture location was not appropriate, such as in the superficial or deep femoral artery (five patients) and in the common femoral artery, above the inguinal ligament (one patient). The arterial puncture was closed by manual compression in five patients at the end of catheterisation and a sealing device was used for the six others (Table 1).

All patients had their PA successfully sealed immediately after the first attempt of injection and compression. The mean volume injected was $47 \pm 11 \mathrm{ml}$ of solution and the mean compression time was $6 \pm 3$ minutes. There was no recurrent PA or bleeding at 24 hours. None required subsequent surgery or any intervention related to the PA. At 30 days, all patients still had their PA closed. Among the seven patients who had a large collected haematoma (Figure 3), the haematoma was partially or totally resorbed in six patients. One patient had persisting haematoma of the thigh at 30 days and was further followed. At three months the haematoma size had significantly decreased. The patient with retroperitoneal haematoma had a rapid and favourable evolution after transfusion of one blood unit and PA closure. The size of the peritoneal haematoma was not subsequently reassessed.

The security of the intervention was satisfying. There was no vascular complication, and no soft tissue infection. Overall, com-

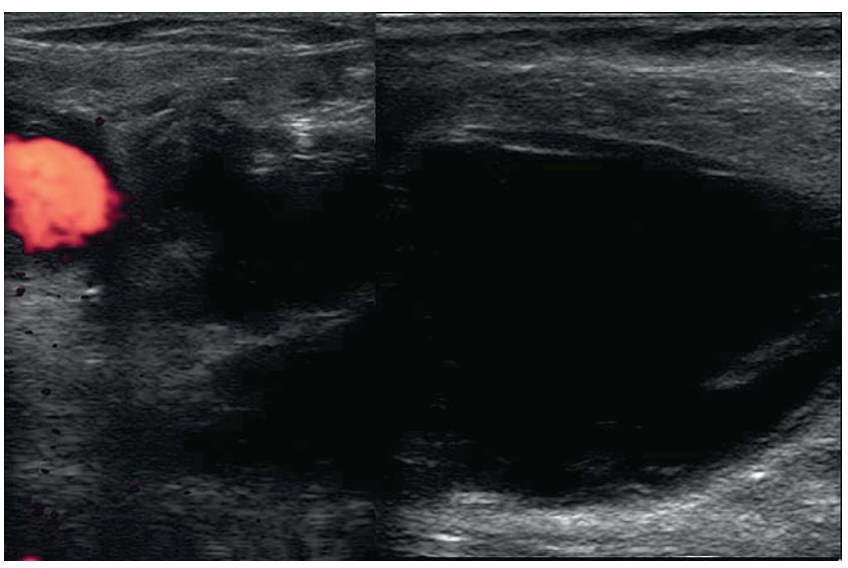

Figure 3. Pulsatile pseudo-aneurysm of the femoral artery,

complicated by a large diffuse and collected haematoma of the thigh.

pression was well tolerated. No patient required sedatives, pain medication or atropine. All patients noticed an immediate release of groin symptoms once the PA was no longer filled by the artery flow. One patient with a large haematoma had mild vagal symptoms during compression (pallor, nausea), without bradycardia or hypotension. This resolved without any medication a few minutes later, once the compression could be released. 


\section{Discussion}

This prospective, uncontrolled study has shown that the compression after saline injection is a safe and very efficient method for sealing iatrogenic PA of the femoral artery. In this study, all patients were cured after a few minutes of compression, despite the use of antiplatelet and antithrombotic treatment. The complex morphology and the large size of PA did not affect the efficacy of the treatment. The method does not require substantial materials or a particular environment such as operating room or angiography laboratory. Therefore, the intervention can be rapidly performed once the PA is diagnosed. This study shows that, after a small amount of training, patients with haemodynamic instability can be cured very quickly.

Compared to the other treatment options, this method has numerous advantages. Previously, PA closing was attempted by simple or echo-guided compression. The technique was easy, but had a low success rate. The mean compression time required for PA closure is around 30 minutes $^{3,4}$. Antiplatelet and antithrombotic therapy increase that time and reduce the chance of success. The major limitation to success is the difficulty to close the neck by compression for a sufficient amount of time to allow thrombosis of the neck. This is due to poor patient tolerance of the strong pressure applied. Severe vagal reaction due to pain may complicate the intervention and these reactions are avoided by the large dose of local anaesthesia provided by the new technique.

Percutaneous injection of bovine or human thrombin in the PA cavity requires a precise echo-Doppler analysis of the PA anatomy and blood flow, before the thrombin is injected. In appropriate cases, 100 to 300 thrombin units are injected into the PA cavity under sonographic control, resulting in an immediate PA thrombosis. The method is very efficient, but has a low risk of arterial embolisation and thrombosis, if the neck is large and short. There is also a risk of sensitisation to bovine thrombin, which has been lowered by the use of recombinant human thrombin ${ }^{5,6}$. The cost of thrombin preparation is high (around 300 Euros) and has a short expiry date.

Endovascular repair may be useful to stop the flow in the PA by inflating an occlusion balloon in the artery, in regard to the flowing point. This can be combined with percutaneous thrombin injection in the PA cavity. Covered stents have been used in the superficial or deep femoral artery, to close large flowing point. However, the cost and the long-term result of stent placement in this area should prompt us to keep this option as a bailout therapy only, to avoid surgery.
Surgical cure usually requires a large incision to allow clamping of the artery proximally and distally to the flowing point. This increases the length of hospital stay and may be complicated by wound infection, lymphoedema, or deep vein thrombosis. The intervention may also be a risk for patients who had a recent myocardial infarction. The cost of the surgical option is also much higher and it should be reserved for PA refractory to all other options.

In conclusion, this study confirms our experience that saline injection is an efficient and safe way to cure post-catheterisation PA of the femoral artery, and is much cheaper and comfortable for the patient than other options. Provided that these results are confirmed in larger studies, we encourage all endovascular clinics to test this method and to adopt it as the first line intervention for all PA.

\section{Conflict of interest statement}

The authors have no conflict of interest to declare.

\section{References}

1. Imsand D, Hayoz D. Current treatment options of femoral pseudoaneurysms. VASA. 2007;36:91-95.

2. Lamonica M, Sidoli A, Barthélémy P, Alimi Y, Elias M, Poggi JN, Giauffret F, Leandri JJ, Elias A. Traitement des faux anévrysmes artériels post-cathétérisme femoral par injection percutanée de sérum physiologique. Abstract. 8ème congrès de la Société Française de Médecine Vasculaire, Toulouse, 8-10 octobre 2009.

3. Görge G, Kunz T, Kirstein M. A prospective study on ultrasound-guided compression therapy or thrombin injection for treatment of iatrogenic false aneurysms in patients receiving full-dose antiplatelet therapy. Z Kardiol. 2003;92:564-570.

4. Chatterjee T, Do DD, Mahler F, Meier B. A prospective randomized evaluation of non-surgical closure of femoral pseudoaneurysm by compresion device, with or without ultrasound guidance. Catheter Cardiovasc Interv. 1999;47:304-9.

5. Chapman WC, Singla N, Genyk Y, McNeil JW, Renkens KL Jr, Reynolds TC, Murphy A, Weaver FA. A phase 3, randomized, double-blind comparative study of the efficacy and safety of topical recombinant human thrombin and bovine thrombin in surgical hemostasis. J Am Coll Surg. 2007;205:256-65.

6. Vázquez V, Reus M, Piñero A, Abellán D, Canteras M, Espinosa de Rueda M, Morales D, Parrilla P. Human thrombin for treatment of pseudoaneurysms: comparison of bovine and human thrombin sonogram-guided injection. Am J Roentgenol. 2005;184: 1665-71. 